\title{
Mathematical model for the evaluation of risk of emergency situations at a dangerous technical object based on artificial neural networks
}

\author{
Nikolay Peganov ${ }^{1}$, Aleksandr Tumanov ${ }^{1 *}$, and Vladimir Tumanov ${ }^{2}$ \\ ${ }^{1}$ Peter the Great Saint Petersburg Polytechnic University, 195251 Polytechnicheskaya st.29, Russian \\ Federation \\ ${ }^{2}$ St. Petersburg State Forest Technical University, 194021 Institutskij pereulok 5, Russian Federation
}

\begin{abstract}
In the work performed adaptation of artificial neural networks in modern security systems potentially dangerous technical objects high-rise buildings as tools for assessing and forecasting in management decision. The study obtained the main scientific results: the mathematical model of risk assessment of man-made emergencies based on artificial neural networks; the mathematical model, adapted to the cumulative model of development technogene emergency-fire; provided risk assessment technique manmade emergencies based on artificial neural networks; represented private man-made fire risk assessment methodology using artificial neural networks.
\end{abstract}

\section{Introduction}

Modern methods of risk assessment are nothing more than a set of all possible methods of assessment, analysis and security of a particular object. At the moment the number of known methods of tens, but not all of them found practical application, and left only a hypothetical model in relation to security. In addition, it is worth noting that the problem is that not all existing modern knowledge applied in the field. So, for example, a great impetus to the development of the security management system has been the emergence of risk assessment $[1,2]$, based on the theory of probability. Therefore, we can conclude that any of the promising direction or even a parallel region will be able to give impetus to the further development of the theory of security. Proof of this is the extensive integration in the safety of the most advanced ideas: modern integrated security systems [3], based on the software-hardware complex; the application of mathematical analysis in reliability. Despite the large number of methods, the quality of the risk assessments have not yet at a sufficient level therefore requires consideration of innovative methods in this area. This can be attributed, and the adaptation of artificial neural networks, further ANN.

The aim of this work is to improve the quality of risk assessment of emergency situations at hazardous activities through adaptation of artificial neural networks (ANN) in

*Corresponding author: toumanov@mail.ru 
modern security systems. The targets set for the implementation of the above objectives the following: an analysis of concepts of artificial neural networks, their architecture; adaptation of neural network by applying an integral development model for evaluating the development emergency hazards of man-made fire.

\section{Mathematical model}

Artificial neural networks in general understanding constitute a mathematical model and its software or hardware incarnation, built on the principle of organization and functioning of the biological neural networks-networks of nerve cells alive the body [4]. Generalized model of biological neuron was introduced back in 1943 year Makkalak and Pits [4], presented in Fig. 1 and the analytical version (1).

$$
a(x, w)=\sigma(\langle w, x\rangle)=\sigma\left(\sum_{j=1}^{n} w_{j} f_{j} x\right)
$$

Where is, $f_{j} ; X \rightarrow R, j=1, \ldots, n$ - numeric signs

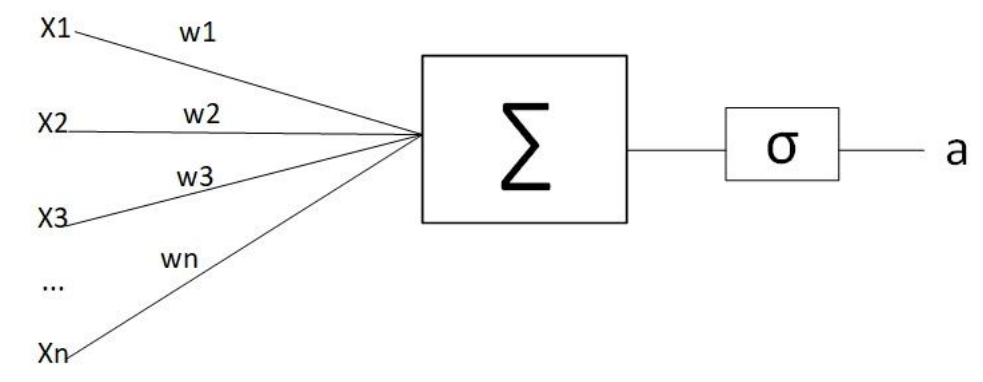

Fig. 1.Biological neuron Model [4] where x 1, ..Xn-input parameters; $\mathrm{W}_{11}, \mathrm{w}_{1 \mathrm{~h}} \ldots \mathrm{w}_{\mathrm{nH}}$-weight of the relevant parameters; $\sigma$-neuron activation function.

The figure shows that the neuron is a "black box", which enters a few parameters, and leaves only one option, provided that the neuron active according to a specific function activation. Because neural network consists of more than one neuron, then it follows that the network itself is superposition of individual neurons. This hypothesis is reflected in the ideas, and then the Perceptron in layered neural networks, Fig. 2.

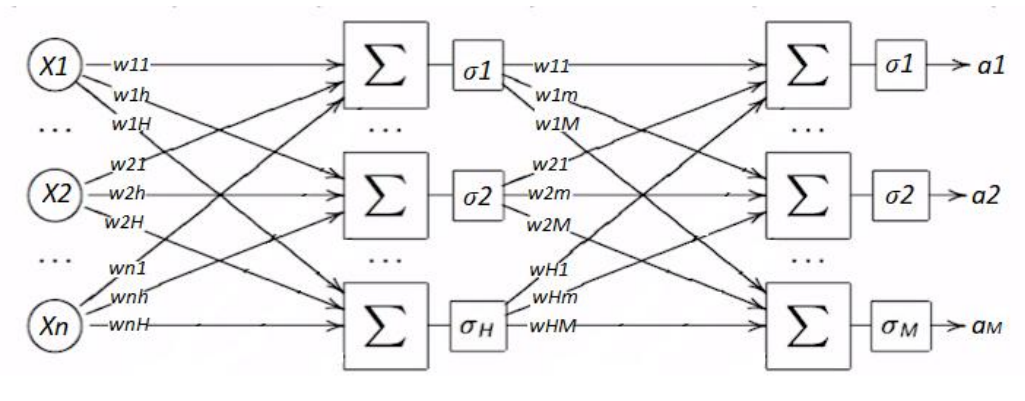

Fig. 2.Multilayer neural network where $\sigma 1, \sigma 2, \ldots, \sigma \mathrm{M}$-activating neurons; A1, a2, am-output parameters relevant neurons.

To solve the problems by using ANN, consider the following situation: indoor complex dangerous technical object, such as a high-rise building or a floating nuclear power plants going explosion and fire, which resulted in the fire and hazardous factors of fire (hereinafter 
FHF). The problem is adequately predict fire development and its FHF and then deciding to manage the system. In General, this question has a solution in the form of modern security systems installations (hereinafter SS), automatic fire extinguishing systems, preliminary modeling of fire development, with a view to analysing the proliferation FHF, etc. [5]. However, this work will be considered a special case of this adverse event. Namely, the design, configuration and run ANN in the hardware-software complex of modern SS.

In this scenario, the neural networks based on a mathematical model for calculating cumulative laid gas exchange during a fire in the building [5]. Basis of this model make up expression of gas flow between rooms (1), the equation of mass balance and optical density (2), (3) energy conservation equation (4), the equation for determining gas temperature and concentration of combustion products in the premises buildings (5), main gas law equation:

$$
G_{j i}=\operatorname{sign}\left(\Delta P_{j i}\right) \cdot \xi \cdot F \cdot \sqrt{2 \cdot \rho \cdot\left|\Delta P_{j i}\right|}
$$

where:

$G_{j i}$ - Gas consumption through a doorway between the two ( $\mathrm{j}$ and $\mathrm{i}$ ) adjacent premises, $\mathrm{kg} / \mathrm{s}$;

$\xi$-discharge coefficient of aperture ( $\xi=0.8$ for closed openings и $\xi=0.64$ for open);

$\mathrm{F}$ - cross-sectional area of the doorway, $\mathrm{m}^{2}$;

$\rho$ - the density of the gases passing through the doorway, $\mathrm{kg} / \mathrm{m}^{3}$;

$\Delta P_{j i}$ - the average difference between complete $\mathrm{j}$ and $\mathrm{i}$ location, PA.

$$
d\left(\rho_{j} \cdot V_{j}\right) / d t=\psi+\sum_{k} G_{k}-\sum_{i} G_{i}
$$

where:

$V_{j}$ - room volume, $\mathrm{m}^{3}$;

$\mathrm{t}$ - time, c;

$\sum_{k} G_{k}$ - expenditure included in the room rate, $\mathrm{kg} / \mathrm{s}$;

$\sum_{i} G_{i}-$ the cost of premises, $\mathrm{kg} / \mathrm{s}$;

$\psi$ - burnout speed of fire load, $\mathrm{kg} / \mathrm{s}$.

$$
d\left(C_{v} \cdot \rho_{j} \cdot V_{j} \cdot T_{j}\right) / d t=C_{p} \cdot \sum_{k}\left(T_{k} \cdot G_{k}\right)-C_{p} \cdot T_{j} \cdot \sum_{i}\left(G_{i}+Q_{\Gamma}-Q_{w}\right)
$$

where:

$C_{v}, C_{p}-$ specificizohornaja and isobaric heat capacity, $\mathrm{KJ} /(\mathrm{kg} * \mathrm{k})$;

$T_{i}, T_{j}$ - the temperature of the gases in the $\mathrm{i}$ and $\mathrm{j}$ indoors, $\mathrm{K}$;

$Q_{\Gamma}$ - the amount of heat generated indoors by combustion, $\mathrm{kW}$;

$Q_{w}$ - heat flow absorbed by structures and emitted through openings, $\mathrm{kW}$. 


$$
V_{j} \cdot d \mu_{j} / d t=\psi \cdot D_{m}+\sum_{k}\left(\mu_{k} \cdot G_{k}\right) / \rho_{k}-\mu_{j} \cdot \sum_{i} G_{i} / \rho_{j}
$$

where:

$\mu_{i}, \mu_{j}-$ optical smoke density in the $\mathrm{i}-\mathrm{m}$ and $\mathrm{j}$-m premises;

$D_{m}$ - forming ability of fire load,

$$
\begin{aligned}
& T_{n j}=\frac{\sum_{k=1}^{n}\left(C_{\mathrm{P} \mathrm{B}} \cdot G_{k} \cdot T_{k}\right)+Q_{j}}{C_{\mathrm{v} 2} \cdot\left(\sum_{k=1}^{n} G_{k}-\sum_{i=1}^{m} G_{i}\right)+C_{\mathrm{pr}} \cdot \sum_{i=1}^{m} G_{i}+\alpha_{j n}^{*} \cdot F_{j n}+\alpha_{j \mathrm{cr}}^{*} \cdot F_{j \mathrm{cr}}}+ \\
& +\left\{T_{(n-1) j}-\frac{\sum_{k=1}^{n}\left(C_{\mathrm{P} \mathrm{B}} \cdot G_{k} \cdot T_{k}\right)+Q_{j}}{C_{\mathrm{v} 2} \cdot\left(\sum_{k=1}^{n} G_{k}-\sum_{i=1}^{m} G_{i}\right)+C_{\mathrm{pr}} \cdot \sum_{i=1}^{m} G_{i}+\alpha_{j n}^{*} \cdot F_{j n}+\alpha_{j \mathrm{cr}}^{*} \cdot F_{j \mathrm{cr}}}\right\rfloor . \\
& \cdot \exp \left\{-\frac{C_{\mathrm{v} 2}\left(\sum_{k=1}^{n} G_{k}-\sum_{i=1}^{m} G_{i}\right)+C_{\mathrm{pr}} \cdot \sum_{i=1}^{m} G_{i}+\alpha_{j n}^{*} \cdot F_{j n}+\alpha_{j \mathrm{cr}}^{*} \cdot F_{j \mathrm{cr}}}{C_{\mathrm{v} 2} \cdot \rho_{j} \cdot V_{j}} \cdot \Delta \tau\right\}
\end{aligned}
$$

where:

$Q_{j}$ - the amount of sources (sewage) heat in a volume of $\mathrm{j}$-facilities and equipment to heat, retiring in enclosures;

$\alpha^{*}=\alpha \cdot\left[\frac{T(\tau)-T_{w}(\tau)}{T(\tau)-T_{0}}\right]-$ given the coefficient of heat transfer;

$T_{0}$ - initial temperature indoors;

$F_{j \text { ст }}$ - the surface area of the frame structures in $\mathrm{j}$ indoors.

When adapting an integrated mathematical model [5] in artificial neural networks, in the above expressions one can distinguish two kinds of parameters: the constant (the volumes of space, initial temperature, the initial pressure, specific heat capacity, etc.), as well as calculated parameters (number of heat in a room different coefficients, etc.). Regarding both types of neural network parameters will be initial parameters to find the summary results that need user for management decision. If you apply these settings regarding a multi-layer neural network (fig. 2.), you can propose a mathematical model of primary and result parameters in ANN, proposed in table 1. 
Table 1. Mathematical model adapted for integrated development model of fire at a dangerous technical object.

\begin{tabular}{|c|c|c|c|}
\hline $\begin{array}{c}\text { Serial } \\
\text { number }\end{array}$ & $\begin{array}{c}\text { Intervals of variable values of input } \\
\text { parameters, } \\
X_{1}-X_{n}\end{array}$ & Weights, w & $\begin{array}{l}\text { Intervals of output } \\
\text { parameters, } a\end{array}$ \\
\hline 1 & $\begin{array}{l}\text { Values with an electronic } \\
\text { thermometer, } 20 \ldots \mathrm{Nt}^{\circ} \mathrm{C}\end{array}$ & \multirow{7}{*}{$\begin{array}{c}\text { Calculated on } \\
\text { the basis of the } \\
\text { learning process } \\
\text { ANN }\end{array}$} & $\begin{array}{l}\text { Design temperature of gas } \\
\quad \text { indoors, } 0 \ldots T_{n j}, K\end{array}$ \\
\hline 2 & $\begin{array}{c}\text { Volumes of premises, } \\
0 \ldots \mathrm{Nv}, \mathrm{m}^{3}\end{array}$ & & $\begin{array}{l}\text { Concentrations of hazardous } \\
\text { factors of fire, } 0 \ldots \mathrm{Ad}, \%\end{array}$ \\
\hline 3 & Dynamic pressure, $100 \ldots \mathrm{N}, \mathrm{KПа}$ & & \multirow{3}{*}{$\begin{array}{c}\text { Change optical density, } \\
\text { No...Ao }\end{array}$} \\
\hline & & & \\
\hline 4 & $\begin{array}{c}\text { Unit heat, } \\
C_{\mathrm{v}}, C_{p}, \mathrm{KJ} /(\mathrm{kg} * \mathrm{k}) ;\end{array}$ & & \\
\hline & & & \multirow{2}{*}{$\begin{array}{l}\text { The concentration of the } \\
\text { individual components of a } \\
\text { gas mixture, } X_{\mathrm{Lj}(\mathrm{n})}, \mathrm{kg} / \mathrm{kg}\end{array}$} \\
\hline 5 & $\begin{array}{c}\text { Optical smoke density in the } \mathrm{i} \text { and } \mathrm{j} \\
\text { (measured by instruments) } \\
0 \ldots \text { No }\end{array}$ & & \\
\hline
\end{tabular}

On the basis of intervals of values, you can perform the initial configuration of ANN, and further her education, with a view to forecasting the FHF as well, further, and the adoption on the basis of this management decision. Training a neural network consists of the following aspects:-the destination array data (Fig. 2) is a collection of numbers, based on which, in the future maybe the adoption of managerial decisions (intervals of variable values of the input parameters, $\mathrm{X}, 1-\mathrm{Xn}$ ); -Once became known the output (output parameters and intervals) it is possible to perform learning ANN. The process of machine learningwill occur at this stage. The user specifies the input parameters, as well as settings that wait. Training will automatically pick weights $\mathrm{w}$, and configures the dependence between input and finite intervals.

\section{Results}

It is worth noting that learning occurs in several iterations, until the rejection of the results:

- as a result of the above transactions the neural network as a tool for forecasting was formed. To solve the problem of management decision to build additional ANN, who is trained in the same way as neural network for prediction, only without the prior calculations. As a result of the work of the neural network to the output we get managerial decision. If you think of an example, the following view is emerging:

- output array data from previous neural network and become inputs for new neural networks;

- you know that under certain parameters some result occur (favourable or adverse event), so the output will be determined ANN. In other words, this operation will produce an automatic decision, and provide it to the user in the system security;

- as a result of neural network learning system will turn the decision in accordance with [6] (in the context of the considered emergency decision based on providing user 
information with a reasonable degree of accuracy, for example, about case of fire and its dangerous affect factors). Thus, in the course of this work carried out adaptation of artificial neural networks in modern security systems as tools for assessing and forecasting in management decision.

\section{Conclusions}

The study obtained the main scientific results:

the mathematical model of risk assessment of man-made emergencies based on artificial neural networks;

the mathematical model, adapted to the cumulative model of development technogene emergency-fire;

provided risk assessment technique manmade emergencies based on artificial neural networks provided private man-made fire risk assessment methodology using artificial neural networks.

\section{References}

1. D. Tarkhov, A. Vasilyev, Optical Memoryand Neural Networks (Information Optics), 14 (1) (2005)

2. A. Vasilyev, D. Tarkhov, G. Guschin, Proceedings of the 10th IMEKO TC7 International Symposium onAdvances of Measurement Science, 2 (2004)

3. V. Gumenyuk, A. Tumanov, Technology of civil safety, 1 (51) (2017)

4. A. Tumanov, Nauchno-tekhnicheskie vedomosti SPbGPU, 2 (171) (2013)

5. V. Gumenyuk, A. Tumanov, Problemy bezopasnostii chrezvychainykh situatsii, 1 (2017)

6. V. Gumenyuk., E. Ryabinina, A. Tumanov, N. Khlobystin, Security management in emergency situations (Ed. Polytech, Saint Petersburg, 2017) 